\title{
Crowdfunding Platforms as Focal Actors in an Entrepreneurial Ecosystem: An Interdisciplinary Value Perspective
}

\author{
Othmar M Lehner \\ Said Business School \\ University of Oxford \\ olehner@acrn.eu
}

\begin{abstract}
Research into Crowdfunding (CF) rarely uses a holistic view on the role of relevant actors and their activities. We thus demonstrate this gap and need from literature and apply an ecosystem perspective to study the influence of crowdfunding platforms (CFPs) as focal actors on the field from a neo-institutional perspective. We look at the structure (focus on interaction through activities) and affiliation (focus on interconnectedness of actors) of multiple case studies of CFPs and ventures to develop five propositions that enable us to build early theory on CF as an entrepreneurial ecosystem that includes an apt conceptualization of the interconnectedness between actors and activities, positions and links in order to create value - with CFPs as powerful central actors.
\end{abstract}

\section{Introduction}

Crowdfunding ( $\mathrm{CF}$ ) denominates a set of innovative financing options for ventures which opens novel investment opportunities for corporate as well as private investors. The heterogeneous "crowd" funds either projects or whole ventures through the aggregation of small individual investments from a large number of investors [1-3]. The supplied capital types range from donations via a simple pre-financing of products and short-term loans to full scale equity investments; all of which differ in regimes, rewards and complexity. Compared to traditional capital markets, crowdfunding is less regulated but therefore bears an inherent risk and hence is limited in funding size [4]. Paschen [5] provides an overview of crowdfunding-typologies, identifies a potential nexus of these with the valuecreation strategies and relevant business models of ventures in different stages and, derives recommendations for the optimum funding type for each stage.

The crowd itself is still a largely unknown phenomenon when it comes to the inner decisionmaking processes and motivations [3, 4, 6, 7]. Members of the crowd are typically globally dispersed and use

\author{
Theresia Harrer \\ Leibniz University Hannover \\ theresa.harrer17@gmail.com
}

social media to exchange ideas and inform themselves to build collective knowledge - the so called "wisdom of the crowd" [8]. That is enabled by crowdfunding platforms (CFPs), which serve as information brokers between the capital seeking ventures and the crowd. These platforms typically offer a range of services and typically generate their revenue streams by taking a percentage of the transaction volume [9-11]. Belleflamme, et al. [12] explore the economic forces at play that influence the design of these platforms from an organizational level. Platforms do differentiate in their business models per CF typologies, introducing for example thresholds and maximum limit concepts to address viability concerns from investors. Because of this, they attract different investors and ventures.

Empirical evidence in $\mathrm{CF}$ is often either provided via reductionist approaches, linking the predicted outcome only to a small set of attributes of $\mathrm{CF}$ campaigns, or via case studies focusing on single actors and levels while examining for example the inner workings of ventures and the interplay with the crowd [13]. Few articles look at CF from a more abstract, holistic perspective by including actors and activities, positions and links; apart from early works for example by Lin and Shih [10] and by Lehner [14] in the realm of crowdfunding for social ventures. Yet, such endeavour may well provide the necessary transition from a phenomenon-driven research that is so far often based on individual levels of inquiry, towards a much-needed theory building.

Especially the role of the CFPs as centralized actors who potentially influence the whole system via their various service offerings and by controlling the resource-flows has remained largely unaddressed so far. Early insights are provided for example by Maier [15], who looks at the necessity for platforms to initiate a double switching behaviour in borrowers and investors. Other voices such as Haas, et al. [16] provide a typology of CFPs, and Lin and Shih [10] look at the role of project teams. Both provide valuable insights from their specific levels, but the interrelatedness of the various actors and their power structures for example remain mostly unnoticed.

Transferring the theoretical concept of an entrepreneurial ecosystem from local regions [17] to the global socio-technical system of CF, we follow Adner 
[18] in defining "ecosystem" as "the alignment structure of the multilateral set of partners that need to interact in order for a focal value proposition to materialize." (p. 40). Adner [18] points out two distinct perspectives on ecosystems. The first one, ecosystemas-affiliation looks at the interdependence of the actors, the potential for synergy or even symbiosis, and focuses on questions of the centrality and power of focal actors. The second one, ecosystem-as-structure looks specifically at the alignment and the interaction through activities that is necessary for a certain value proposition. In this, he identifies four distinctive elements (p. 43): Activities, as discrete actions undertaken to achieve the promised value proposition, Actors, as entities that undertake these activities and exert a power influence, Positions, which localize the actors and allow identification of workflows and Links, as transfers of various resources, including power, funds but also information.

The objectives of this research endeavour are thus to identify the specific activities provided by CFPs [19] and to critically assess the role of CFPs as focal actors in forming, enabling and restricting crowdfunding from an institutionalist standpoint [20].

Following this we look at the power-structures in the relative positioning of the actors and at the links for resource transfers. Based on the findings of 23 exemplary cases of CFPs and ventures we finally build early theory on $\mathrm{CF}$ as an entrepreneurial ecosystem based upon five inductively developed propositions. With this we are expanding and following research from Haas, et al. [16] and Belleflamme, et al. [12].

\section{State of the Art in CF Research}

When looking at the dynamics of success and failure of crowdfunding $(\mathrm{CF})$, the role of personal networks and the perception of project quality as predictors can be seen as focal [2]. Addressing the first, Kuppuswamy and Bayus [21] provide longitudinal insights on the dynamics of project support over time by examining the moderating factors on the effects of goal proximity. They find that the predicted positive effect of goal proximity in a threshold CF model is accentuated by small target goals and limited early support. Such findings thus help understand timing effects on the crowd motivation.

Decomposing the somewhat generic, yet excessively applied term "crowd", numerous authors look at the role of social capital and community processes in CF campaigns. Applying a Bordieuan lens, Lehner [8] finds evidence that CF success depends on how efficient interaction between different tiers of social capital transforms builds a common cultural capital that is necessary for the transformation into economic capital. In this transformation, he examines how these interaction processes are strongly moderated by the progressively built cultural and symbolic capital, for example through patents [22] of the CF seeking venture.

Colombo, et al. [11] corroborate the above findings in a large-scale quantitative setting and ascertains that the internal social capital of the whole crowdfunding community is indeed affecting its success. As predicted in Lehner [8], actions that take place in the early-stages such as enlisting a critical number of backers and the resulting early capital flow serve as accelerators for the previously mentioned transformation process.

To this, Josefy, et al. [7] outline that addressing a community with a strong geographical fit to the intended opportunity and the focus on the cultural attributes of this community is vital for entrepreneurs who are attempting to tap the crowd internationally. Distance, as outlined before, can also be overcome by emitting signals to various networks via CFPs in order to translate the value propositions and activate social capital. What is more, Butticè, et al. [24] look at how serial crowdfunding acts as a strong signal for social capital and ultimately project success. Such signals also matter in subsequent stages when it comes to attracting venture capital and bank funding for scaling up.

The interaction between potential funders and the crowd generates trust and improves social capital. However, little is known how collaboration informs and influences opportunity recognition and exploitation and thus ultimately innovation and value propositions [25]. Valančienė and Jegelevičiūtė [26] specifically look at the role of stakeholders and how they influence the processes in which value is created. In addition, they see the dual identities of customers and suppliers as users and backers and discuss the shifting role of financial institutions and their influence on value creation. Burns, et al. [27] describe this process accordingly as stakeholder enrolment and define it as a critical factor for forming and exploiting opportunities.

Venture specific human capital, social capital, intellectual capital and the perceived uncertainty [28] can be thus be as critical dimensions in order to predict $\mathrm{CF}$ success. What becomes clear by looking at the studies mentioned above is that in all examined processes very different actors in very different power situations are involved in this network of activities. For example, the perceptions and inner workings of individual members of the crowd influence the organizational outcome of a venture based on the presented opportunity at-hand and above all, the powerful central node of a CFP provides the links and at the same time moderates the resource flow by translating cultural capital. This demonstrates the need for introducing a systems perspective in form of an 
ecosystem lens to build theory and transcend the perspectives of the individual actors, thus recognizing the complex interplay of individuals, organizations and the crowd.

Providing additional evidence of the high importance of CFPs as focal actors in such an ecosystem, Jääskeläinen and Maula [29] find that platforms can address issues of cultural distance and potential biases by transforming signals and information into a community-relevant cultural context, thus creating the impression of a virtual locality. Combining this with the above findings, CFPs thus can act as boundary spanner not only between the different actors, but also between geographical and physical locations of the ventures.

Further demonstrating the powerful central position of CFPs, Vismara [30] looks at "information cascades" that signify the link of external public profiles of investors and investees to the information available at the CFP. This fits well with earlier explanations by Reuber and Fischer [31], who discuss the importance of online technological capabilities and online reputation in internet enabled markets and see that platforms work as moderators in the pursuit of opportunities.

Finally, applying a legitimacy lens, Frydrych, et al. [32] explore how legitimacy is created by specifically targeted constitutional elements of a crowdfunding campaign. With respect to the prior mentioned perspectives they highlight the role of CFPs as actors that bundle not only different interests, but also the varying linguistic and constitutional elements of campaigns.

Summing up, two important insights emerge. First, the processes that lead to a successful CF campaign use signals that need to be built and transferred in a twoway communication to engage with a culturally adapted social capital. Second, these processes bring with a complex system of interactions between the actors that has the potential to generate value and ultimately drive a successful CF campaign. The above reviewed literature deals well with many of these facets individual, yet $C F$ as an entrepreneurial ecosystem, that transcends the levels of intra- and inter-organizational research and combines viewpoints on actors and their positioning with that of resource links in order to generate value through joint activities has not been addressed so far and becomes the central objective of this article.

\section{Ecosystems and CF Platforms}

We follow the work of Adner [18], who defines ecosystem as: "the alignment structure of the multilateral set of partners that need to interact in order for a focal value proposition to materialize” (p. 40) together with a grammar for the characterization of the ecosystem structure by distinguishing between: actors, positions, links and activities. Reflecting on the state of the art in CF research as outlined in the previous section we understand crowdfunding as an entrepreneurial ecosystem from a neo-institutional perspective and apply Adner's grammar accordingly in our empirical inquires.

In the literature, networked ecosystems are strongly linked to value creation because they help to overcome resource-bottlenecks and innovation challenges in firms [33]. In what Adner [18] calls an ecosystem-asaffiliation perspective, the focus of inquiries would be on "the breakdown of traditional industry boundaries, the rise of interdependence and the potential for symbiotic relationships" (p. 41).

We thus aim to not only look at the role of CFPs as single actors or as intermediaries that broker financial flows and by that reduce information asymmetries and transaction costs; rather we aim to provide insights into the transformative character of the crowdfunding industry as a whole. Addressing this seems especially relevant for phenomena such as crowdfunding that are strongly linked to a socio-economic context, because it shows the need to include societal perspectives in any attempt to build theory.

Of particular relevance in such an ecosystem are the questions of network density and the centrality of some focal actors in larger networks. A focal actor seems to increase system value through direct and indirect network externalities [34]. Platforms in a CF ecosystem can thus be seen as such focal actors as they influence existing institutions and regimes. Early approaches can be found in Wang, et al. [35], who adapt a persuasive systems design to come up with a CFP design model.

Finally, our research also builds on Haas, et al. [16], who provide a CFP typology based on Hedonism, Altruism and For-Profit, and Belleflamme, et al. [12], who explore the economic forces at play that influence the design of these platforms from an organisational level.

\section{Methodology}

The objectives of this research endeavour are to identify the specific activities provided by CFPs and to critically assess the role of CFPs as focal actors in forming, enabling and restricting crowdfunding from a neo-institutionalist standpoint [20].

Based on the findings of 23 purposefully sampled cases of various types, sizes and industries from eleven different CFPs, with a total funded sum of 77,210,781 USD, a range of: $43,724,820$ and average of: $3,356,990$, we finally build early theory on CF as an entrepreneurial 
ecosystem based upon five inductively developed propositions from a neo-institutional perspective.

The purposeful selection of the cases was based upon the criteria of being either exemplary as identified in the literature, or exceptional [36] - with these characteristics being identified from a media reception analysis in the Forbes magazine over the years 20142017. The cases and platforms were examined in-depth through the collection of primary and secondary documents, interviews with founders and platform managers and ethnographic observations, leading to over 300 individual documents. The sampling was deemed pseudo-complete after a theoretical saturation criterion of "no new codes after 2 additional cases" was reached. A full list of the cases and documents can be downloaded via the QR code in figure 1, with a aggregated sample overview in table 1 .

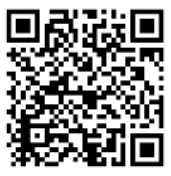

Figure 1 - QR Code to the document list and case descriptions.

\begin{tabular}{llll}
\hline $\begin{array}{l}\text { Origin } \\
\text { Country: }\end{array}$ & Types: & Industry: & Summary: \\
\hline US: 16 & Reward: 9 & Hi-Tech: 8 & from 11 \\
UK: 3 & Equity: 8 & Hygiene: 1 & platforms \\
AUS: 2 & Donation: 3 & Tourism: 3 & 23 cases \\
OTHERS: & InDemand: 1 & Social: 2 & 308 docs \\
2 & Lending: 2 & Software: 4 & 1901 codes \\
& & Consum.: 4 & 3 coders \\
TOTAL:23 & & Personal: 1 & $\begin{array}{l}5 \text { propo- } \\
\text { sitions }\end{array}$ \\
\hline
\end{tabular}

Table 1 - Sampling Overview

This inductive approach holds well with Watson [37], who demands that entrepreneurship research needs to achieve a better balance between studying entrepreneurial activities and setting these activities in their wider context through ethnographic research with concepts from sociology and from pragmatist thinking. Watson further argues that field research should be innovative in combining in-depth studies of several enterprises and their founders with the analysis of broader aspects of 'entrepreneurship in society', by a process of 'everyday ethnographic' observation, reading, conversation and ongoing analysis.

Selected excerpts of the data were first transformed into standardized meaningful units, discarding rhetorical artefacts and then subsequently coded based upon the proven techniques as set out by Denzin and Lincoln [38]. The transformation into meaningful units and the actual coding took place in a multi-coder (3 persons), recursive and iterative process (all documents at least 3 times each with additional codes from others) using the software Atlas.TI, with a continuously developed coding manual and regular discussions between the coders, for example by comparing and contrasting differing findings of the same material. All disputes (84 out of 1901) were settled using a majority system.

True to the inductive nature of the research no apriori codes were applied, yet the previously discussed ecosystem framework of actors, activities, positions and links was used to give structure to the findings later on, following suggestions by Eisenhardt, et al. [39].

The codes were then summarized into five propositions based on the conflux of the findings with the existing literature. In this we follow Cornelissen [40] suggestions on common styles of theorizing and aim to "explain the fuzzy nature of many subjects by logically and causally combining different constructs into a coherent and explanatory set of types" (p. 3). These propositions were then combined to build early theory on $\mathrm{CF}$ as entrepreneurial ecosystem that we further illustrated in a model displaying actors, positions, links and activities.

\section{Empirical Findings}

Using the framework of Adner by distinguishing between actors, positions, links and activities, the following five propositions were developed. The 7-digit numbers in brackets point to the exemplary documents, and the full list of cases and documents can be found on using the $\mathrm{QR}$ link in figure 1. By looking at an example document of the case of Pebble on Kickstarter [0101019], we explain the numbering in detail: The first two digits [01] indicate the platform Kickstarter.com, the second pair of digits $[. .01 \ldots]$ link to the case of the Pebble watch itself and the final three digits [.. .. 019] refer the document number within that platform and case (see link in the QR code in figure 1).

After the individual discussion of the propositions, a summary will be illustrated in figure 2, depicting the CF ecosystem with numbers as links to the propositions.

Proposition 1: CFPs are positioned as trusted platforms and centralized catalogues, providing signals and localized value-translation in order to communicate the legitimacy of the CF-ventures to the Crowd. Looking at the cues and signals that are created throughout a crowdfunding campaign we find that crowdfunding campaigns are used to test market acceptance and estimate demand beforehand [0101000, 0213000, 0221000, 0518000]. The most prominent signals we identified were: funding milestones, early adoption and pledges, media and news reception, public feedback related to both the ideas and the people 
involved, dedicated investment requests from venture capitalists (VCs) inquiring on the progress [0204000], and cross venture backing from other campaigns [0222303, 0222304]. Besides the signals, we found the following cues: the radiance and attire of the entrepreneurial team, the innovativeness of the ideas and the willingness to respond to questions.

In some cases, the signal and marketing perspectives even dominated the crowdfunding motivation of the ventures. As an example, the Nuyu Sleep System [022000] uses the platform Indiegogo to gain customer feedback from early adopters - individuals highly inclined to test new products and services. Because of the collaborative spirit of investors in crowdfunding, said feedback and the interaction with the crowd may well lead to adaptions of the product or business model [0101000] and as such may contribute to a successful market entry. For example, Pebble adapted their watches based on numerous inputs from the crowd and was highly successful in three CF campaigns (total volume of approximately \$44 million [0101241, 001242, 0101243, 0101247] and ultimately positively exited [0101248]. Through signals, including the willingness to adapt, trust is created and ultimately the legitimacy of the ventures is improved. Another example being "MyShowCase" [0310000] who are not primarily seeking funds but rather wanting to build a solid community of customers and partners for their online-run beauty product platform.

From the perspective of (corporate) venture capitalists, CFPs can be seen as a central hub providing a catalogue of innovative ideas and a virtual marketplace for private and corporate investors [0200000] in which the successful funding by the crowd would act as a strong signal to institutional investors and corporations looking to enhance their real options strategies.

Platforms also need to signal their reputation and values to enhance legitimacy. One strategy is to embrace ventures with a strong societal relevance and high chance of success in their portfolios. Some, such as Indiegogo even go so far to create a separate space for social causes. One salient example of a donationbased CF would be the Pencils of Promise [0215000] based on Indiegogo's Generosity.

Another representative example could be the goTenna Mesh project [0107000]. Funded on the platform Kickstarter it enables smartphone owners to communicate without cell-, Wi-Fi or satellite reception in order to assist rescue workers in an emergency situation.

Proposition 2: Strong CPFs as focal actors use their power to enable, but also to influence the configuration of CF-Ventures in their role as gatekeepers. Crowdfunding platforms supply brochures and checklists and provide consulting and expert services [0100022] to aspiring ventures, for example, how to structure their campaigns and create a compelling business story [0100023] or how to better align their business models [0300188]. In some cases, these consulting services also contribute to the income of the platforms but more often they are offered for free as part of the marketing activities. Comparing guides from high profile platforms such as Kickstarter [0100000], Indiegogo [0200000] and Crowdcube [0300000], they all seem to cover the same topics with only nuances of difference.

The resulting uniformity of the campaigns based on the ubiquity of the platforms' idiosyncratic rules and guidelines [0100191, 0200203, 0300190] certainly helps investors to better compare $\mathrm{CF}$ campaigns and thus reduce the transaction costs involved. However, besides the obvious beneficial effects of these activities there are also unforeseen consequences that may be explained through a neo-institutional lens - as the strong influence of the platforms and willingness of the ventures to adapt may well create an unintentional reflexive isomorphic convergence of the ventures, which does not lead to a higher legitimacy but only results in a lesser variability and unfair discrimination of non-conformant campaigns. A reason for this may be that ventures see others follow these sets of guidelines and rules and blindly pursue the same configuration, not because of their success but because of convenience and external pressure by the platforms. This again illustrates the unequal hierarchical power positions of fundseeking ventures and the CFPs as focal actors in the crowdfunding ecosystem.

Besides the role as enabler through the provision of advisory services, CFPs also act as gatekeepers in the selection of ventures, based on an often-discretionary set of rules [0700284, 0700285, 0200206]. In theory, this is meant to increase the quality of the visible campaigns, but because these rules and the duediligence in their execution are often not overly transparent and seem to be rather ad-hoc, platforms again contribute to an isomorphic system and create somewhat unsubstantiated entry-barriers.

Proposition 3: CFPs as central platforms bring together, enable and control the resource-flow between ventures and the crowd as actors for CoCreation and Open-Innovation processes, by making use of rapidly evolving technological infrastructure. Platforms provide the technological base for a two-way communication infrastructure, allowing direct participation of the investors and stakeholders. CFPs can be seen to offer a co-creation space [0100286, 0214092, 0700284, 0800266, 0222000] so that investors and stakeholders can actively contribute to the dynamic formation of the business 
model [0100286, 0800253, 0222000] and participate in relevant decision-making processes [0101300, 0101301, 0106297, 0309302]. Taking in the advice from the crowd, entrepreneurs can adapt to changes in the perceived demand or even follow new opportunities [0700284]. For example, Kickstarter provides a connection tool to other $\mathrm{CF}$ experienced entrepreneurs [0100022, 0700307]. Ventures then can directly contact established and renowned experts to ask their opinion on various potential situations. In addition, direct contact to VC and other corporate investors is provided via specific tools and platforms [0204000].

Through the continuous interaction between the investors, ventures and the platform co-creation is enabled. The question of demands on technological savviness of the crowd using tools for co-creation however has not been addressed so far and may explain the low market share of CF investors from developing countries [9900308].

Proposition 4a: Ventures reach out to other funding sources from actors such as venture capitalists, business angels or even other platforms via CFPs to initiate so called Cascaded-Funding Strategies for scaling.

Proposition 4b: In these Cascaded-FundingStrategies CFPs act as information brokers and repositories for the necessary large-scale and professional Investor Relations that would otherwise overly burden smaller ventures. Ventures not only use platforms for their very early-stage funding but also use $\mathrm{CF}$ more and more to expand their market and scale-up their businesses. For this, ventures often seek a mix of various funding instruments, including debt, equity and reward-based crowdfunding [0517000, 0518148]. In this, one especially important perspective seems to be the chronology and success of the various options, amongst the pitch performance [0116104, 0221218, 0309051, 0516128] and the funding history [0309054, 0412086, 0420178, 0420176]. Early ventures typically start with some form of reward-based CF [010100, 0308000, 0411000] and continue later, after the successful market entry, to seek additional capital in form of debt and equity, either again via a platform or from VCs and banks.

Besides a tailored investment story [0116112, 0200181, 0200183, 0700283, 0800266], one especially relevant strategy for ventures seems to be to create some form of intellectual capital, for example patents to be used as a collateral in the latter stages of the funding process [0102000, 0107000, 0412000, 0619000]. Such stepwise developments need very different communication strategies for each milestone and can thus be seen examined as a "funding cascade". Platforms have to adapt their services in order to attract a variety of investor groups and stay relevant for the ventures' additional funding round intentions. One problem field that we identified, however, is that the presentation of the ventures on dedicated equity $\mathrm{CF}$ platforms needs to be very different to other forms, as cash-flow projections and terminology around profitsharing are more predominant.

An example would be the partnering of the platform Indiegogo with Microventures.com, offering access to a venture capital network, a business-angel community and an equity-crowdfunding platform at the same time. A young distillery in the United States named "Republic Restoratives" [0204000] makes uses the said partnership to further increase their production capacity and market share. Via the equity crowdfunding platform Crowdcube the "Hop Stuff Brewery" [0308000] runs its second campaign to open more bars across the city of London and finance their new packaging which fits the strategy of large-scale exporting. IntaCept Ltd. [0412000] is already running their fourth funding round at the Australian equity-based platform ASSOB in order to further develop their services and products.

Concomitantly with the role of a counselling partner for funding cascades, CFPs can thus also be understood as information brokers between investors of all sorts and the ventures with the ultimate goal of reducing information asymmetries and leading to a successful funding [0100027, 0100028, 0200181, 0200182, 0221217]. What has been found while analysing the provided information is that reporting elements, amongst those concerning risk and Corporate Social Responsibility (CSR) information are often only implicitly referred to, compared to the established standards in traditionally funded ventures.

Most pieces of information provided by the platforms are aiming to overcome the so-called liability of newness of the ventures. The often-short history of the fund-seeking ventures poses a substantial risk bearing significant transaction costs. Platforms address and mitigate this risk by linking to additional sources of information [0204006, 0204007, 0310056].

Proposition 5: Public policy and institutionalized regimes exert and influence CFPs and are in-term influenced by their strong agenda building activities and advocacy. Platforms are not only subjected to regulations themselves [0800252, 9900287, 9900288, 9900291] but also inform and in some cases, influence legislation to improve and enhance the current regulatory status of crowdfunding [0500220, 9900294, 9900295]. In many cases, platforms work together on this to increase their bargaining power and outreach to the relevant authorities. In Europe for example, the European Crowdfunding Network (ECN), a network of many influential platforms and individuals advocate for a common European framework on crowdfunding and inform local governments [0500143]. At the same time, 
it is inherently important for governmental bodies and policy makers to be provided with experts from different perspectives in the new and often poorly understood field of crowdfunding. For example, when former US-president Barack Obama signed the JOBS Act in 2012, many CFPs were part of the development process [9900291] providing their expertise to the Senate and Congress. Alongside business angels, VCs and other experts, the platforms Indiegogo [0200000], Kiva [0700000] and RocketHub [0800000] among many others were involved in the development-process

\section{CF as entrepreneurial ecosystem}

Summing up the five propositions and structuring the discussed findings within an ecosystem-framework, we provide a schema in figure 2 to illustrate the actors, positions, links and related activities in a CF enabled ecosystem, based on a prior version in Lehner [14]. The numbers in this schema correspond to the numbering of the propositions as previously outlined.

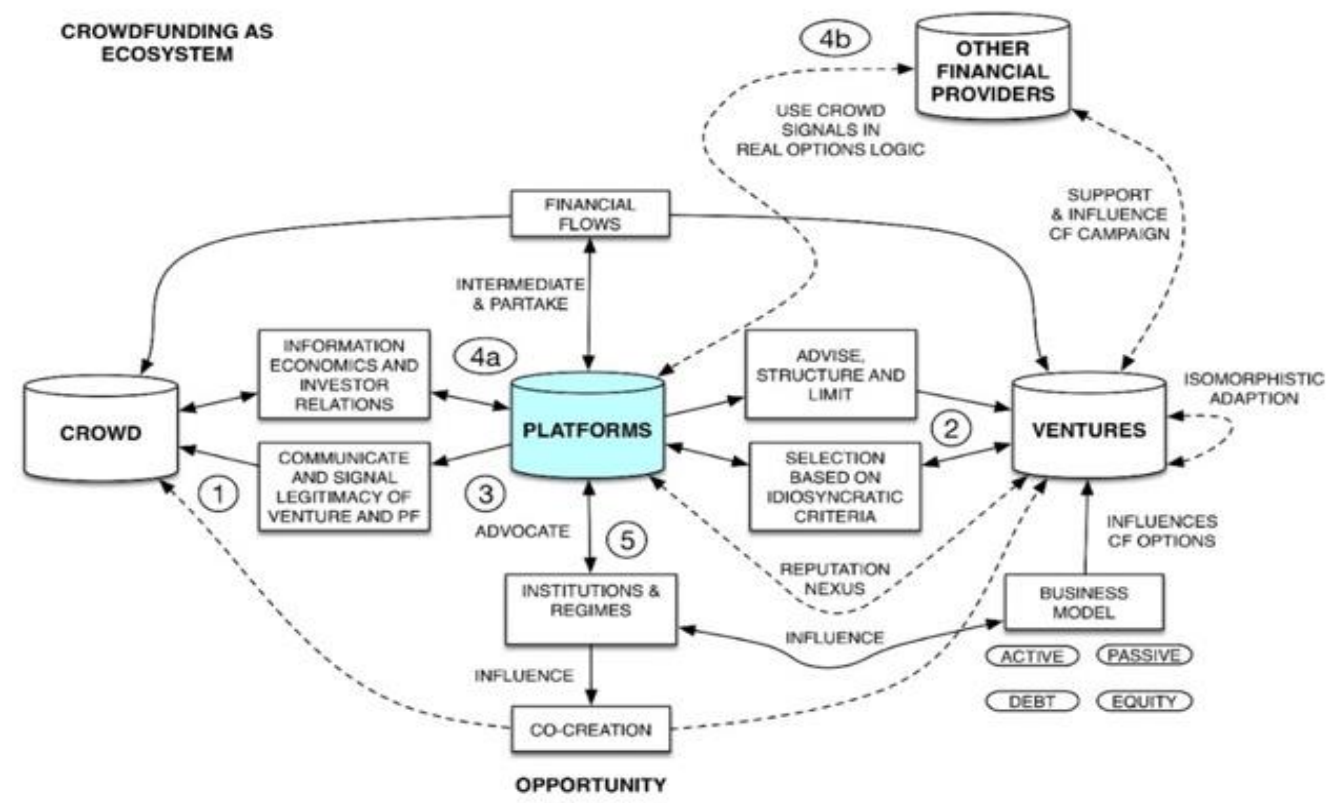

of the JOBS Act. As European examples, Symbid [0600000], a Dutch CFP supports the local legislation in coordinating relevant crowdfunding developmentprocesses and in Austria the platform 1000x1000 [0500000] has played a crucial role in the new act on crowdfunding and crowd investing [0518148]. CFPs thus can be seen as catalysts to initiate negotiations and policy making concerning societal demands as well as the needs of the crowd and the ventures [0500143].

From a more critical perspective, the previously addressed phenomenon of reflexive isomorphism makes it easier for CFPs to regulate and tailor the market to their own business interests, thus potentially overpowering the perspectives of market rivals in the field. What is more, some platforms may need to compromise their own strategy to comply with demands from other powerful players because they rely on corporations, institutions and service co-operations in their business model, as seen in Kiva [0700274, 0700275, 0700276] partnering with the HP or MasterCard foundations or Ernst\&Young as critical stakeholders.
Figure 2. The CF Ecosystem. The numbers indicate propositions 1-5 with bold lines, enhancing the figure from Lehner in [14] (dashed lines)

The choice of a venture to seek funding from the Crowd thus results in numerous inputs from other actors in the system. Platforms function as brokers and in many cases as catalysts to induce and align the necessary processes in actors and the overall system.

Discussing and expanding early theory on CFP from Haas, et al. [16], who identify three archetypes of CFPs based on their aggregated value propositions of hedonism (addressing the investors' sense of interest, desire or joy), altruism (attracting investors with an interest in the greater good) and for-profit (satisfying monetary needs) that purely address the financial role of the platforms, we propose additional ones based on the above developed propositions 1-5: trusted communication partners, gatekeepers, resource catalysts, investor relations professionals, and finally lobbyists. 
Such a view on the granular, on the partial value propositions, helps to create a link to correlative and explanatory research into the business models and the competitive positioning of CFPs in the future - as Demil, et al. [41] state that a business model can be seen as a concept that helps explain various aspects of the underlying phenomenon and provides an inherent source of value which can be accessed through novelty, efficiency, complementarities and lock-ins.

A big player platform such as Kickstarter or Indiegogo will obviously take on many of the abovementioned roles with potential attenuating effects between, whereas small, niche players may just embrace one or two and create a strong profile with the help of these.

\section{Discussion and Conclusion}

Seeing CF not as a simple financing process but as an ecosystem allows us to understand how value is created not only from the individual actors but from their systemic interplay $[17,18,33]$. The five major propositions from our empirical work point out the manifold implications of the activities of CFPs as central actors for all other actors in the field. Many already individually addressed processes in the literature, such as co-creation, can be better understood by looking at the configuration of interplay and motivation between levels of the individual, organizational and societal in an ecosystem. This also follows research from Lipusch, et al. [42] who conceptualize and examine the concept of co-creation in the context of reward-based crowdfunding. With this, we touch on and contribute to research from various disciplines, amongst them entrepreneurship and entrepreneurial finance [1, 43], innovation and opportunity formation [13, 44, 45], but also from sociology and information technology $[16,46]$.

To further bring in critical perspectives, borrowing from established organizational theories including neoinstitutionalism $[32,47]$ and configurational theory $[48$, 49] we thus suggest approaches such as critical discourse analysis [20,50] and the QCA-method [51] to further expand our understanding of CF. Our derived fine-grained value propositions provide structure and ideas for crowdfunding platforms. As a practical implication, this is highly relevant for CFPs, as many are still struggling in their competitive positioning and many have yet to find a sustainable business model. For this, CFPs need additional revenue streams and have to create a unique selling proposition from a marketing point of view - ideally based on their individually selected mix of value propositions.

Future research will also need to look into how specific platform configurations of such value- propositions may be particularly suitable for certain stages of platforms, and how a strategic alignment can take place to achieve a pareto-optimum - of course not excluding potential equifinalities.

For ventures seeking funding from the crowd our research has made clear that the decision has farreaching consequences on their business model and governance as they will exchange funding for a strong stakeholder influence that is moderated by the chosen platform. In order to create a successful campaign, they not only need to perfectly align their early business model with their choice of platform and type of CF, but also need to be aware of signalling effects [52] and understand how their investor-relations need to be configured to appropriately reach the crowd and entice their willingness to co-create.

What is more, the reputation and technology nexus [53] between the ventures and the platform demands a careful selection process from both sides, as the entrepreneurial opportunity and the individual founders' personalities need to match with the value offerings and strategic positioning of the platform.

Taking on the ecosystem perspective also allows a more nuanced understanding of the "whatness" and relevance of the "crowd". Instead of simply tapping the crowd, ventures and platforms need to create customized communication and activation strategies to fully realize the value propositions implied in crowdfunding. Besides funding, these would include the before mentioned co-creation of opportunities, the much needed advocacy in hostile environments [54] and decentralized communication channels for public relations. What becomes clear is that closer research into the crowd needs to be aware of the cultural, geographical, demographical and demoscopical valuespecific perspectives, and we thus also propose to stop seeing "crowd" as a generic concept for such purposes. This reverberates well with McKenny, et al. [55] when they suggest topics for future research and ask "How do cultural traditions influence perceptions of the legitimacy of crowdfunding" (p. 11).

Finally, Nambisan [56] mentions the intersection of digital technologies and entrepreneurship in his work and comes up with the definition of digital entrepreneurship, which depicts another important aspect to consider in $\mathrm{CF}$ ventures as more and more processes are driven by digitalisation and modern $\mathrm{CF}$ would not be possible without digital platforms, Fintechs and data science driven social media. Research on $\mathrm{CF}$ as ecosystem may thus also provide additional insights into the "digital-sphere" of entrepreneurship. 


\section{References}

[1] G. Bruton et al., "New Financial Alternatives in Seeding Entrepreneurship: Microfinance, Crowdfunding, and Peer-to-Peer Innovations", Entrepreneurship Theory and Practice, vol. 39, no. 1, 2015, pp. 9-26.

[2] E. Mollick, "The dynamics of crowdfunding: An exploratory study", Journal of Business Venturing, vol. 29, no. 1, 2014, pp. 1-16.

[3] P. Belleflamme, T. Lambert, and A. Schwienbacher, "Crowdfunding: Tapping the right crowd", Journal of Business Venturing, vol. 29, no. 5, 2014, pp. 585609.

[4] A. R. Stemler, "The JOBS Act and crowdfunding: Harnessing the power-and money-of the masses", Business Horizons, vol. 56, no. 3, 2013, pp. 271-275.

[5] J. Paschen, "Choose wisely: Crowdfunding through the stages of the startup life cycle", Business Horizons, vol. in press, 2016, pp. 1-10.

[6] M. Cholakova and B. Clarysse, "Does the Possibility to Make Equity Investments in Crowdfunding Projects Crowd Out Reward-Based Investments?", Entrepreneurship Theory and Practice, vol. 39, no. 1, 2015, pp. 145-172.

[7] M. Josefy et al., "The Role of Community in Crowdfunding Success: Evidence on Cultural Attributes in Funding Campaigns to "Save the Local Theater"", Entrepreneurship Theory and Practice, vol. 41, no. 1, 2016.

[8] O. M. Lehner, "The formation and interplay of social capital in crowdfunded social ventures", Entrepreneurship \& Regional Development, vol. 26, no. 5-6, 2014, pp. 478-499.

[9] J. Löher, "The interaction of equity crowdfunding platforms and ventures: an analysis of the preselection process", Venture Capital, vol. 19, no. 1-2, 2016, pp. 51-74.

[10] W.-S. Lin and Y.-Y. Shih, "A research framework of crowdfunding platform usage", in 22nd Americas Conference on Information Systems, San Diego, 2016.

[11] M. G. Colombo, C. Franzoni, and C. RossiLamastra, "Internal Social Capital and the Attraction of Early Contributions in Crowdfunding", Entrepreneurship Theory and Practice, vol. 39, no. 1, 2015, pp. 75-100.

[12] P. Belleflamme, N. Omrani, and M. Peitz, "The economics of crowdfunding platforms", Information Economics and Policy, vol. 33, 2015, pp. 11-28.

[13] O. M. Lehner, E. Grabmann, and C. Ennsgraber, "Entrepreneurial implications of crowdfunding as alternative funding source for innovations", Venture Capital, vol. 17, no. 1-2, 2015, pp. 171-189.

[14] O. M. Lehner, "Crowdfunding social ventures: a model and research agenda", Venture Capital, vol. 15 , no. 4, 2013, pp. 289-311.
[15]

E. Maier, "Supply and demand on crowdlending platforms: connecting small and medium-sized enterprise borrowers and consumer investors", Journal of Retailing and Consumer Services, vol. 33, 2016, pp. 143-153.

[16] P. Haas, I. Blohm, and J. Leimeister, "An Empirical Taxonomy of Crowdfunding Intermediaries", in Thirty Fifth International Conference on Information Systems, Auckland, 2014.

[17] B. Spigel, "The Relational Organization of Entrepreneurial Ecosystems", Entrepreneurship Theory and Practice, vol. 41, no. 1, 2017, pp. 4972.

[18] R. Adner, "Ecosystem as Structure: An Actionable Construct for Strategy", Journal of Management, vol. 43, no. 1, 2017, pp. 39-58.

[19] T. E. Brown, E. Boon, and L. F. Pitt, "Seeking funding in order to sell: Crowdfunding as a marketing tool", Business Horizons, vol. in press, 2016.

[20] C. Kalantaridis, "Institutional change in the Schumpeterian-Baumolian construct: power, contestability and evolving entrepreneurial interests", Entrepreneurship \& Regional Development, vol. 26, no. 1-2, 2013, pp. 1-22.

[21] V. Kuppuswamy and B. L. Bayus, "Does my contribution to your crowdfunding project matter?", Journal of Business Venturing, vol. 32, no. 1, 2017, pp. 72-89.

[22] G. Rassenfosse and T. Fischer, "Venture debt financing: Determinants of the lending decision", Strategic Entrepreneurship Journal, vol. 10, no. 3, 2016, pp. 235-256.

[23] H. Zheng et al., "The role of multidimensional social capital in crowdfunding: A comparative study in China and US", Information \& Management, vol. 51, no. 4, 2014, pp. 488-496.

[24] V. Butticè, M. G. Colombo, and M. Wright, "Serial Crowdfunding, Social Capital, and Project Success", Entrepreneurship Theory and Practice, vol. 41, no. 1, 2017, pp. 1540-6520.

[25] N. Mary George et al., "A systematic literature review of entrepreneurial opportunity recognition: insights on influencing factors", International Entrepreneurship and Management Journal, vol. 12, no. 2, 2014, pp. 309-350.

[26] L. Valančienè and S. Jegelevičiūtè, "Crowdfunding for Creating Value: Stakeholder Approach", Procedia - Social and Behavioral Sciences, vol. 156, 2014, pp. 599-604.

[27] B. L. Burns et al., "Enrolling Stakeholders under Conditions of Risk and Uncertainty", Strategic Entrepreneurship Journal, vol. 10, no. 1, 2016, pp. 97-106.

[28] G. K. C. Ahlers et al., "Signaling in Equity Crowdfunding", Entrepreneurship Theory and Practice, vol. 39, no. 4, 2015, pp. 955-980.

[29] M. Jääskeläinen and M. Maula, "Do networks of financial intermediaries help reduce local bias? Evidence from cross-border venture capital exits", 
Journal of Business Venturing, vol. 29, no. 5, 2014, pp. 704-721.

[30] S. Vismara, "Information Cascades Among Investors in Equity Crowdfunding", Entrepreneurship Theory and Practice, vol. 41, no. 1, 2016, pp. 1-31.

[31] A. R. Reuber and E. Fischer, "International entrepreneurship in internet-enabled markets", Journal of Business Venturing, vol. 26, no. 6, 2011, pp. 660-679.

[32] D. Frydrych et al., "Exploring entrepreneurial legitimacy in reward-based crowdfunding", Venture Capital, vol. 16, no. 3, 2014, pp. 247-269.

[33] R. Adner and R. Kapoor, "Value creation in innovation ecosystems: how the structure of technological interdependence affects firm performance in new technology generations", Strategic Management Journal, vol. 31, no. 3, 2010, pp. 306-333.

[34] S. P. Choudary, M. W. Van Alstyne, and G. G. Parker, Platform revolution: How networked markets are transforming the economy--and how to make them work for you. WW Norton \& Company 2016.

[35] B. Wang, E. Lim, and C. Van Toorn, "Gimme Money! Designing Digital Entreprenurial Corwdfunding Platforms", in PACIS 2016 Proceedings, 2016.

[36] M. A. Uy, M. D. Foo, and H. Aguinis, "Using Experience Sampling Methodology to Advance Entrepreneurship Theory and Research", Organizational Research Methods, vol. 13, no. 1, 2009, pp. 31-54.

[37] T. J. Watson, "Entrepreneurship in action: bringing together the individual, organizational and institutional dimensions of entrepreneurial action", Entrepreneurship \& Regional Development, vol. 25, no. 5-6, 2013, pp. 404-422.

[38] N. Denzin and Y. Lincoln, The Sage handbook of qualitative research, Third Edition (books.google.com). Sage Publications Ltd., London 2005.

[39] K. M. Eisenhardt, M. E. Graebner, and S. Sonenshein, "Grand Challenges and Inductive Methods: Rigor without Rigor Mortis", Academy of Management Journal, vol. 59, no. 4, 2016, pp. 1113-1123.

[40] J. Cornelissen, "Editor's Comments: Developing Propositions, a Process Model, or a Typology? Addressing the Challenges of Writing Theory Without a Boilerplate", Academy of Management Review, vol. 42, no. 1, 2017, pp. 1-9.

[41] B. Demil et al., "Introduction to theSEJSpecial Issue on Business Models: Business Models within the Domain of Strategic Entrepreneurship", Strategic Entrepreneurship Journal, vol. 9, no. 1, 2015, pp. 111.

[42] N. Lipusch et al., "Innovating Beyond the Fuzzy Front End: How to Use Reward-Based Crowdfunding to Co-create with Customers", in
Hawaii International Conference on System Sciences (HICSS 2018), Hawaii, 2018.

[43] M. Wright et al., "The Evolving Entrepreneurial Finance Landscape", Strategic Entrepreneurship Journal, vol. 10, no. 3, 2016, pp. 229-234.

[44] N. J. Foss and T. Saebi, "Fifteen Years of Research on Business Model Innovation: How Far Have We Come, and Where Should We Go?", Journal of Management, vol. 43, no. 1, 2016, pp. 200-227.

[45] J. Partanen, S. K. Chetty, and A. Rajala, "Innovation Types and Network Relationships", Entrepreneurship Theory and Practice, vol. 38, no. 5, 2014, pp. 1027-1055.

[46] A. Paradkar, J. Knight, and P. Hansen, "Innovation in start-ups: Ideas filling the void or ideas devoid of resources and capabilities?", Technovation, vol. 4142, 2015, pp. 1-10.

[47] J. Su, Q. Zhai, and T. Karlsson, "Beyond Red Tape and Fools: Institutional Theory in Entrepreneurship Research, 1992-2014", Entrepreneurship Theory and Practice, vol. 40, no. 4, 2016.

[48] J. L. Woolley, "The Creation and Configuration of Infrastructure for Entrepreneurship in Emerging Domains of Activity", Entrepreneurship Theory and Practice, vol. 38, no. 4, 2014, pp. 721-747.

[49] M. Gruber et al., "Configurations of resources and capabilities and their performance implications: an exploratory study on technology ventures", Strategic Management Journal, vol. 31, no. 12, 2010, pp. 1337-1356.

[50] B. L. Connelly et al., "The Power and Effects of Entrepreneurship Research", Entrepreneurship Theory and Practice, vol. 34, no. 1, 2010, pp. 131149.

[51] S. Stiller, "The interplay of actor-related strategies and political context: a fuzzy-set QCA analysis of structural reforms in continental welfare states", Journal of European Public Policy, vol. 24, no. 1, 2017, pp. 81-99.

[52] A. R. Reuber and E. Fischer, "Signalling reputation in international online markets", Strategic Entrepreneurship Journal, vol. 3, no. 4, 2009, pp. 369-386.

[53] J. Löher, "The interaction of equity crowdfunding platforms and ventures: an analysis of the preselection process", Venture Capital, vol. 19, no. 1-2, 2017, pp. 51-74.

[54] D. F. Kuratko et al., "Is your organization conducive to the continuous creation of social value? Toward a social corporate entrepreneurship scale", Business Horizons, 2017.

[55] A. F. McKenny et al., "How Should Crowdfunding Research Evolve? A Survey of the Entrepreneurship Theory and Practice Editorial Board", Entrepreneurship Theory and Practice, 2017.

[56] S. Nambisan, "Digital Entrepreneurship: Toward a Digital Technology Perspective of Entrepreneurship", Entrepreneurship Theory and Practice, vol. 40, no. 5, 2016, pp. 1-27. 